\title{
Delay in Seeking Care for Sexually Transmitted Diseases in Young Men and Women Attending a Public STD Clinic
}

\author{
Angela M. Malek ${ }^{*}, 1$, Chung-Chou H. Chang ${ }^{2}$, Duncan B. Clark ${ }^{3}$ and Robert L. Cook ${ }^{4}$ \\ ${ }^{I}$ Department of Neurosciences, Medical University of South Carolina, Charleston, SC, USA \\ ${ }^{2}$ Departments of Medicine and Biostatistics, University of Pittsburgh, Pittsburgh, PA, USA \\ ${ }^{3}$ Departments of Psychiatry and Pharmaceutical Sciences, University of Pittsburgh, Pittsburgh, PA, USA \\ ${ }^{4}$ Departments of Epidemiology and Medicine, University of Florida, Gainesville, FL, USA
}

\begin{abstract}
Background: Delay in seeking care for sexually transmitted diseases (STDs) has adverse consequences for both the individual and population. We sought to identify factors associated with delay in seeking care for STDs.

Methods: Subjects included 300 young men and women (aged 15-24) attending an urban STD clinic for a new STDrelated problem due to symptoms or referral for an STD screening. Subjects completed a structured interview that evaluated STD history, attitudes and beliefs about STDs, depression, substance use, and other factors possibly associated with delay. Delay was defined as waiting > 7 days to seek and obtain care for STDs.

Results: Nearly one-third of participants delayed seeking care for $>7$ days. Significant predictors for delay included selfreferral for symptoms as the reason for visit (OR 5.3, 95\% CI: $2.58-10.98$ ), and the beliefs "my partner would blame me if I had an STD" (OR 2.44, 95\% CI: 1.30 - 4.60) and "it's hard to find time to get checked for STDs" (OR 3.62, 95\% CI: 1.95 - 6.69), after adjusting for age, race, sex, and other factors. Agreeing with the statement "would use a STD test at home if one were available" was associated with a decrease in delay (OR 0.24, 95\% CI: 0.09 - 0.60).

Conclusions: Many young persons delay seeking care for STDs for a number of reasons. Strategies to improve STD careseeking include encouragement of symptomatic persons to seek medical care more rapidly, reduction of social stigmas, and improved access to testing options.
\end{abstract}

Keywords: Delay, healthcare-seeking behavior, men, sexually transmitted diseases, symptoms, women.

\section{INTRODUCTION}

Sexually transmitted diseases (STDs) have a significant impact on many men and women of reproductive age [1]. Nearly half of the 19 million new STDs diagnosed in the U.S. each year occur among persons aged 15-24 years [2]. Delay in seeking care for STDs can result in transmission to others, increase the risk of acquiring further infections (including HIV), or increase the likelihood of consequences such as infertility and chronic pelvic pain. Previous research suggests that $20 \%$ to $50 \%$ of persons delay seeking care and testing for STDs by more than a week; with many waiting a month or more [3-5]. Therefore, emphasizing early diagnosis and management of STDs are crucial public health strategies.

In general, STD clinics serve as a place where persons with STD-related concerns or symptoms seek care [6]. Many individuals are referred to STD clinics for testing or evaluation, often by a sexual partner who has been diagnosed with an STD or by another healthcare provider due to STDrelated concerns. Over 2 million people utilize STD clinics

*Address correspondence to this author at the Department of Neurosciences, College of Medicine, Medical University of South Carolina, 19 Hagood Avenue, Suite 501, Charleston, SC 29425, USA; Tel: 843-792-9590;

Fax: 843-792-2484; E-mail: malek@musc.edu in the U.S. each year, most of whom are young, of low socioeconomic status, and are of nonwhite minority groups [7]. Young men and women attending STD clinics represent a population at increased risk for STDs and HIV infection and among whom delay in seeking care might be especially harmful. Furthermore, home-testing for STDs is becoming more common [8-11] and could reduce delay in obtaining testing. However, it remains unclear whether persons who delay seeking care in clinics would be more likely to use a self-test at home compared to persons who already seek care rapidly.

Barriers to care-seeking may be related to individual factors (e.g. attitudes, social stigma, mental or physical health conditions) or health system factors (clinic or testing factors) [3-5, 12-18]. Several previously conducted studies have found women tend to delay seeking care longer than men, especially if the visit is due to symptoms $[3-5,18]$. Women with symptoms often delay seeking care because they believe the symptoms are normal or unrelated to STDs, and thus may initially wait for the symptoms to subside.

The primary objectives of our study were to: identify individual and clinic-based factors associated with delay in seeking care for STDs among young people attending an STD clinic, determine whether these factors varied according 
to gender, and assess potential interest in the use of home STD-self-testing and whether interest varied in persons who sought care rapidly and those who delayed seeking care.

\section{METHODS}

\section{Subjects and Recruitment}

Participants $(n=448)$ were recruited from a Pittsburgh metropolitan area urban STD clinic between 1999 and 2002. The clinic provided free STD testing, diagnosis, and treatment to approximately 150 individuals each week. Details of the study methods have been published previously [19]. The study received approval from the University of Pittsburgh Institutional Review Board and all participants provided written informed consent. In brief, men and women were eligible to participate if they were 15-24 years of age and had received a clinical assessment for a new STD-related problem. Of the 448 total participants in the parent study, this analysis was limited to 300 young men and women indicating the reason for their clinic visit as due to the presence of STD-related symptoms (symptomatic, $n=189$ ) or referral by a sexual partner or health care provider for STD screening (asymptomatic referral, $\mathrm{n}=111$ ). Persons seeking a general check-up or screening test were excluded from these analyses because a specific delay interval could not be determined.

All participants provided written informed consent, and each received a monetary compensation of $\$ 20$ to $\$ 40$, as determined by the length of the interview related to selfreported substance use. Those reporting substance use additionally completed a youth-specific version of the Structured Clinical Interview for Diagnostic and Statistical Manual-IV diagnosis (SCID) (DSM-IV) and were asked further questions about the frequency and duration of use in the past year in order to assess the presence of a past-12months' substance use disorder involving alcohol or marijuana [20].

\section{Measures}

Following the clinical assessment for STDs, a trained female interviewer administered the questionnaire in-person to participants. The questionnaire asked about demographic and clinical characteristics, whether the partner had a new STD, previous history of STDs, the timing of their decision to seek care, and also assessed the presence of alcohol/substance abuse or dependence, as previously described. Clinically relevant depressive symptoms were defined as a score of 24 or greater on the 20 -item Center for Epidemiological Studies-Depression Scale (CES-D) [21]. A current STD was defined as a laboratory-confirmed diagnosis of chlamydia, gonorrhea, trichomoniasis, or a new clinical diagnosis of genital herpes or warts. Proximity to the clinic was categorized as living within city limits or not.

The investigators were not aware of a validated measure to assess delay in seeking care for STDs at the time of the study. Therefore, to assess attitudes and beliefs of STDs, sexual behavior, and health in general, we included 21 items suggested in a model that outlines a broad set of possible factors that could influence STD healthcare seeking behavior [22]. These included individual factors and those related to clinic or structural factors, such as: attitudes/beliefs about STDs, having a primary care physician, visiting the dentist, exercise, diet, alcohol/drug use, risky/dangerous behavior, etc. [22]. Subjects' consideration of using an STD test at home, if one were available, was also examined as previous research has suggested development of home tests as an alternative testing method [8-11]. Ratings for the items were based on a 6-point Likert scale that ranged from "strongly agree" to "strongly disagree." For analysis purposes and due to the small number of responses in each category, the responses were dichotomized to "agree" or "disagree." The specific questionnaire items are available from the authors by request. We conducted an exploratory factor analysis in order to combine related attitudes and beliefs into a scale, but no groupings were significant and therefore all variables were treated as individual attitudes and beliefs.

Participants were asked to state the number of days prior to the clinic visit that they: 1) first noted symptoms (if symptomatic) or were referred to the clinic by either a sexual partner or health care professional (if asymptomatic); 2) thought they had a problem that needed evaluation (after experiencing symptoms or being referred); and 3) decided to seek care. The Total Care-Seeking Interval was defined as the number of days between the time a person first noticed symptoms (if symptomatic) or from being referred to get tested for an STD (if asymptomatic referral) and the time of the actual clinic visit.

\section{Statistical Analysis}

African-American $(n=178)$ and other non-white racial/ethnic groups $(n=17)$ were combined for the analysis as few participants were identified as Hispanic, biracial, or as persons of a non-specified race. The primary outcome variable, Total Care-Seeking Interval, was highly skewed, with $70 \%$ of subjects seeking care within 7 days, and $3 \%$ waiting more than 100 days before seeking care. Thus, we categorized Total Care-Seeking Interval as those who sought care rapidly ( $\leq 7$ days) or those who delayed seeking care (> 7 days) because delay in seeking care by more than 7 days has been associated with significant health outcomes and was the cut point used by most other studies on this topic [3, $4,23,24]$. Although defined as "delay in seeking care", this period refers to the entire span of time an at-risk STD patient undergoes before completing STD screening, with at-risk defined as the experience of STD symptom or referral by partner/healthcare provider.

Descriptive statistics included the chi-square and Fisher's exact test to compare categorical variables and to determine the association of delay with individual characteristics, risk behavior, and attitudes and beliefs. To identify factors that were independently associated with care-seeking, logistic regression was performed, including age, race, gender, variables of clinical significance, and all variables that were significant in bivariate analysis at $\mathrm{p}<0.05$ and removing variables at $\mathrm{p}<0.10$. Thus, the following predictors were initially selected for multivariable modeling: presence of symptoms, age, race, gender, insurance, living outside city limits, "STD clinics keep records confidential", "would consider using an STD test at home if one were available", "more likely to get an STD test without genital exam", "getting to the STD clinic is easy", "it's hard to find time to get checked", and "my partner would blame me if I had an STD." All analyses were conducted within the entire sample 
and separately by gender. If predictors of the outcome appeared to be different in males and females, interaction terms were tested in the overall model to determine whether any of the interactions were statistically significant.

Two-tailed tests were used and $p$-values $<0.05$ were considered statistically significant. All analyses were conducted with SAS version 9.1.3 and Statistical Package for the Social Sciences (SPSS) Statistics, version 19 [25, 26].

\section{RESULTS}

The study cohort included a total of 300 young men and women between the ages of 15-24 years who indicated the reason for their clinic visit as due to the presence of STDrelated symptoms (symptomatic, $n=189$ ) or referral by a sexual partner or health care provider for STD screening (asymptomatic referral, $\mathrm{n}=111$ ). The mean age was 20.4 years, half were male, and $54 \%$ were Caucasian or white. Twenty percent were between the ages of $15-18,46 \%$ were $19-21$, and $34 \%$ were $\geq 22$ years of age. Fifty-nine percent $(n=176)$ reported an annual income of $<\$ 20,000$. Insurance status varied among participants as thirty-eight percent had private insurance, eighteen percent had Medicaid, and fortyfour percent of participants did not have health insurance. Twenty-six percent of participants lived within city limits. In addition, $39 \%$ were diagnosed with a new STD at the clinic visit, and $25 \%$ reported having been diagnosed with an STD in the previous 12 months.

Among the 300 study subjects, 211 (70\%) sought care within 7 days. Of those who sought care within 7 days, 15 (7\%) sought care on the day of symptoms or referral for STD screening, 62 (29\%) sought care within 1 day, and 134 (64\%) sought care within 3 days. Thus, $30 \%$ or nearly onethird delayed seeking care for more than 7 days. Among those with symptoms, $38 \%$ of men and $39 \%$ of women delayed seeking care for more than 7 days. Among asymptomatic persons referred to treatment, men were somewhat more likely to delay than women, although the difference was not statistically significant (19\% vs 9\%).

In bivariate comparisons, persons were significantly $(p<0.01)$ more likely to delay seeking care if they were Caucasian or white, or if symptoms were the reason for visit ( $v s$ asymptomatic referral) (Table 1). Individuals were also significantly more likely to delay if they agreed that "my partner would blame me if I had an STD" $(p<0.05)$ and "it's hard to find time to get checked for an STD" $(p<0.01)$. Young persons were less likely to delay seeking care if they agreed that "getting to the STD clinic is easy", or "STD clinics keep records confidential" (Table 1). Age, gender, depression, current substance use disorder, as well as other attitudes and beliefs (individual and clinic factors) were among the factors not significantly associated with delay.

Results were similar when stratified by gender, although females were significantly more likely to delay if they agreed that "most people think you are a bad person for getting tested for STDs" (Table 1). The relationship of other factors and delay in seeking care in males and females are shown in Table $\mathbf{1}$.

Interest in home testing for STDs was also assessed, and a similar proportion of men $(93 \%)$ and women $(88 \%)$ stated that they would consider using an STD test at home if one were available. Persons who were interested in home testing were also less likely to delay seeking care.

The final multivariable model, including all participants, identified four factors that were independently associated with delay in seeking care after adjusting for age, race, sex, and the following factors or beliefs: live outside of city, insurance, "getting to the STD clinic is easy," "STD test clinics keep records confidential, and "more likely to get an STD test without genital exam." Symptomatic persons were more likely to delay seeking care for STDs compared to asymptomatic referrals ( $\mathrm{OR}=5.32,95 \% \mathrm{CI}: 2.58,10.98)$ (Table 2). The beliefs "it's hard to find time to get checked" $(\mathrm{OR}=3.62$, 95\% CI: 1.95, 6.69) and "my partner would blame me if I had an STD" (OR=2.44, 95\% CI: 1.30, 4.60) were also associated with a delay in seeking care for STDs. Agreeing with the statement, "would use a STD test at home if one were available" (OR=0.24, 95\% CI: $0.09,0.60)$ was associated with a decrease in delay, indicating that persons who came to the clinic earlier were also interested in using a STD test at home.

In multivariable models stratified by gender and following adjustment, all of the factors remained significantly associated with delay for males except for the belief, "my partner would blame me if I had an STD". Among females, the presence of symptoms and the beliefs "it's hard to find time to get checked" and "my partner would blame me if I had an STD" were significantly associated with delay. In addition, agreeing with the statement, "more likely to get an STD test without a genital exam" was associated with a decrease in delay among females. None of the gender*factor interaction terms were statistically significant, indicating that none of the factors were substantially more relevant in one gender than the other.

\section{DISCUSSION}

STD clinics are accessed by more than 2 million people with STD-related symptoms or concerns in the U.S. each year, of which the majority are young, of minority groups, and of low socioeconomic status [6,7]. Persons attending STD clinics are among the highest risk group for STD and HIV infection that exist and thus represent an important population through which prevention of further disease transmission as well as reduction of delay in seeking care efforts could be targeted. In this study, factors associated with delay in seeking care for STDs were identified and compared among 300 adolescents and young adults attending a free STD clinic. In multivariable analysis, the factors most significantly associated with delay in seeking care for $>7$ days included the presence of symptoms ( $v s$ asymptomatic referral), difficulty finding time to get checked at the clinic, and belief that a partner would blame you for having an STD. These findings suggest that individual health issues (symptoms), factors associated with access to clinic services, and some individual attitudes and beliefs impact care-seeking for STDs.

Delays in STD care-seeking and testing are important public health issues due to both the communicable nature of STDs (person-time of infectiousness) and the risk of 
Table 1. Number and Proportion of Young Men and Women Attending an STD Clinic in Pittsburgh from 1999-2002 who Delayed Seeking STD Care for $>7$ days, by Selected Characteristics

\begin{tabular}{|c|c|c|c|c|c|c|}
\hline & \multicolumn{2}{|r|}{ Overall } & \multicolumn{2}{|r|}{ Men } & \multicolumn{2}{|c|}{ Women } \\
\hline \multicolumn{7}{|l|}{ Age } \\
\hline$<22$ years & 198 & $56(28)$ & 96 & $28(29)$ & 102 & $20(20)$ \\
\hline \multicolumn{7}{|l|}{ Race } \\
\hline Caucasian or white & 105 & $39(37) *$ & 57 & $22(39)$ & 48 & $17(35)$ \\
\hline Non-white & 195 & $50(26)$ & 92 & $24(26)$ & 103 & $26(25)$ \\
\hline \multicolumn{7}{|l|}{ Annual income ${ }^{a}$} \\
\hline Medicaid & 54 & $13(24)$ & 16 & $6(38)$ & 38 & $7(18)$ \\
\hline Private & 113 & $31(27)$ & 55 & $14(25)$ & 58 & $17(29)$ \\
\hline None & 133 & $45(34)$ & 78 & $26(33)$ & 55 & $19(35)$ \\
\hline \multicolumn{7}{|l|}{ Reason for visit } \\
\hline Symptoms & 189 & $73(39) * *$ & 92 & $35(38) *$ & 97 & $38(39) * *$ \\
\hline Asymptomatic referral & 111 & $16(14)$ & 57 & $11(19)$ & 54 & $5(9)$ \\
\hline \multicolumn{7}{|c|}{ Substance use disorder (alcohol or drugs) } \\
\hline Yes & 128 & $37(29)$ & 79 & $20(25)$ & 49 & $17(35)$ \\
\hline Live within city limits & 212 & $56(26)$ & 98 & $26(27)$ & 114 & $30(26)$ \\
\hline Live outside city limits & 88 & $33(38)$ & 51 & $20(29)$ & 37 & $13(35)$ \\
\hline \multicolumn{7}{|l|}{ Attitudes, Beliefs, Knowledge } \\
\hline \multicolumn{7}{|l|}{ Individual Factors } \\
\hline \multicolumn{7}{|c|}{ STDs almost always cause symptoms } \\
\hline Agree & 151 & $49(32)$ & 69 & $26(38)$ & 82 & $23(28)$ \\
\hline Do not agree & 149 & $40(27)$ & 80 & $20(25)$ & 69 & $20(29)$ \\
\hline \multicolumn{7}{|c|}{ You can generally tell if partner has STD } \\
\hline Agree & 61 & $18(30)$ & 32 & $12(38)$ & 29 & $6(21)$ \\
\hline Do not agree & 239 & $71(30)$ & 117 & $34(29)$ & 122 & $37(30)$ \\
\hline \multicolumn{7}{|c|}{ My partner would blame me if I had STD } \\
\hline Agree & 175 & $62(35) * *$ & 103 & $35(34)$ & 72 & $27(38) *$ \\
\hline Do not agree & 125 & $27(22)$ & 46 & $11(24)$ & 79 & $16(20)$ \\
\hline \multicolumn{7}{|c|}{ No way to get STD if always use condom } \\
\hline Agree & 53 & $20(38)$ & 24 & $10(42)$ & 29 & $10(35)$ \\
\hline Do not agree & 247 & $69(30)$ & 125 & $36(29)$ & 122 & $33(27)$ \\
\hline
\end{tabular}


(Table 1) contd....

\begin{tabular}{|c|c|c|c|c|c|c|}
\hline & \multicolumn{2}{|r|}{ Overall } & \multicolumn{2}{|r|}{ Men } & \multicolumn{2}{|c|}{ Women } \\
\hline & Total & $\begin{array}{l}\text { Delayed Care } \\
\text { Seeking, n (\%) }\end{array}$ & Total & $\begin{array}{l}\text { Delayed Care } \\
\text { Seeking, n (\%) }\end{array}$ & Total & $\begin{array}{c}\text { Delayed Care } \\
\text { Seeking, n (\%) }\end{array}$ \\
\hline \multicolumn{7}{|l|}{ STDs are not serious health problem } \\
\hline Agree & 25 & $11(44)$ & 11 & $5(46)$ & 14 & $6(43)$ \\
\hline Do not agree & 275 & $78(28)$ & 138 & $41(30)$ & 137 & $37(27)$ \\
\hline \multicolumn{7}{|c|}{ Most would think you are a bad person for getting tested for STDs } \\
\hline Agree & 114 & $39(34)$ & 59 & $17(29)$ & 55 & $22(40) *$ \\
\hline Do not agree & 155 & $50(32)$ & 59 & $29(32)$ & 96 & $21(22)$ \\
\hline \multicolumn{7}{|l|}{ Clinic Factors } \\
\hline \multicolumn{7}{|l|}{ Hard to find time to get checked } \\
\hline Agree & 119 & $56(47) * *$ & 67 & $29(43) * *$ & 57 & $27(47) * *$ \\
\hline Do not agree & 181 & $33(18)$ & 87 & $17(20)$ & 94 & $16(17)$ \\
\hline \multicolumn{7}{|l|}{ Getting to the STD clinic is easy } \\
\hline Agree & 265 & $73(28) *$ & 132 & $37(28) *$ & 133 & $36(27)$ \\
\hline Do not agree & 35 & $16(46)$ & 17 & $9(53)$ & 18 & $7(39)$ \\
\hline \multicolumn{7}{|l|}{ Getting checked for STD is embarrassing } \\
\hline Agree & 147 & $51(35)$ & 77 & $27(35)$ & 70 & $24(34)$ \\
\hline Do not agree & 153 & $38(25)$ & 72 & $19(26)$ & 81 & $19(24)$ \\
\hline \multicolumn{7}{|l|}{ STD test clinics keep records confidential } \\
\hline Agree & 280 & $78(28) * *$ & 133 & $38(29)$ & 147 & $40(27) * *$ \\
\hline Do not agree & 20 & $11(55)$ & 16 & $8(50)$ & 4 & $3(75)$ \\
\hline \multicolumn{7}{|l|}{ More likely to get STD test without genital exam } \\
\hline Agree & 151 & $38(25)$ & 82 & $24(29)$ & 69 & $14(20) *$ \\
\hline Do not agree & 149 & $51(34)$ & 67 & $22(33)$ & 82 & $29(35)$ \\
\hline \multicolumn{7}{|l|}{ Home Testing for STDs } \\
\hline \multicolumn{7}{|l|}{ Would consider STD test at home if available } \\
\hline Agree & 272 & $76(28) *$ & 139 & $41(30)$ & 133 & $35(26)$ \\
\hline Do not agree & 28 & $13(46)$ & 10 & $5(50)$ & 18 & $8(44)$ \\
\hline
\end{tabular}

Abbreviations: STD = Sexually transmitted disease.

Statistical comparison of persons who delayed $>7$ days according to the presence of an individual characteristics or belief compared to persons who did not delay seeking care: ${ }^{*} p<0.05$, ** $p<0.01$.

${ }^{a} A$ Annual income was not reported by 5 participants.

${ }^{\mathrm{b}}$ Depression measured as CES-D score $>=24$; Substance use disorder according to DSM-IV criteria for alcohol or marijuana abuse or dependence.

individual health consequences (pelvic inflammatory disease) [27, 28]. In our sample, two attitudes/beliefs stood out most strongly as independently associated with delay and suggest that both clinic-related variables and individual attitudes and beliefs are associated with delay. The first, "it's hard to find time to get checked for STDs", suggests that either persons don't prioritize the STD visit in relation to their competing activities, or that the clinic is not accessible at the time they would like to use it. In urban settings, STD clinics are often available several days a week with limited night and weekend access; however, in settings where access to an STD clinic is more limited, delay could be longer. Integration of STD services with other clinical services has therefore been suggested as a way to avoid the stigma as well as other factors that may cause some persons to delay care [29]. The other attitude that remained significant in multivariable modeling, "my partner would blame me if I had an STD”, suggests that either social stigma related to STDs, or concerns about relationships and their outcomes, could impact test seeking.

We sought to identify any gender differences in factors associated with delays in seeking care. Overall, there were minimal differences in time to care-seeking by gender, and the factors and attitudes and beliefs associated with delay were similar. In univariate analysis, women referred by a sexual partner or health care provider to get tested for STDs (asymptomatic referrals) tended to seek care sooner than men, although the difference was not significant. This is consistent with previous studies reporting the increased likelihood of women, in general, to utilize health care services compared to men [30-32]. Multivariately, females indicating they would be "more likely to get an STD test without a genital exam" were found to delay less. No other 
Table 2. Factors Associated with Delay in Seeking Care Among 300 Young Men and Women Attending an STD Clinic: Multivariable Logistic Regression

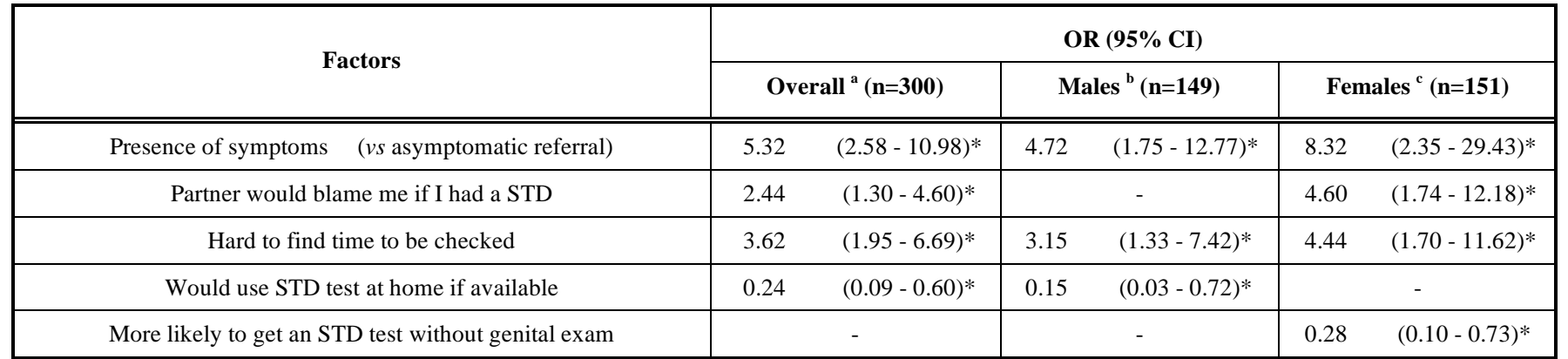

Abbreviations: STD $=$ Sexually transmitted disease, $\mathrm{OR}=$ Odds ratio, $\mathrm{CI}=$ Confidence Interval, $v s$, versus.

$*=$ Statistically significant at $p<0.05$. - = Variable not significant in the model.

${ }^{a}$ Overall model adjusted for: age, race, gender, live outside of city, getting to the STD clinic is easy, STD test clinics keep records confidential, more likely to get an STD test without genital exam, and insurance.

${ }^{b}$ Male model adjusted for: age, race, live outside of city, getting to the STD clinic is easy, STD test clinics keep records confidential, more likely to get an STD test without genital exam, partner would blame you if you had a STD, and insurance.

${ }^{\mathrm{c}}$ Female model adjusted for: age, race, live outside of city, getting to the STD clinic is easy, STD test clinics keep records confidential, would use a STD test at home if available, and insurance.

significant differences in delay in care-seeking for STDs were found. This is in contrast to many other studies exploring differences by gender that found symptomatic women tended to delay longer than symptomatic men $[4,5$, 18], whereas few studies have failed to find significant differences [27].

Consistent with other studies, individuals with symptoms tended to delay longer than those without symptoms but who had been referred to be checked [23]. This is a perplexing aspect of STD care-seeking behavior, as people with symptoms may avoid care because they choose to wait and see if symptoms disappear, think the symptoms may be normal, try self-treatment, or may avoid care due to embarrassment or denial [5, 23]. In contrast, individuals without symptoms who are referred by a friend, sexual partner, or health care provider to get checked for an STD, may be more convinced to seek care quickly.

Home testing for STDs has been proposed as one method to avoid barriers of STD testing including self-testing strategies that use urine samples or self-collected vaginal swabs. We had hypothesized that persons who delayed seeking care at an STD clinic might be more likely to be interested in home testing. Although a majority of our participants indicated they would consider using an STD test at home if one were available, the fact that persons most interested in home testing or non-invasive testing were also less likely to delay seeking care suggests that individuals who are interested in getting tested more quickly would also be most likely to adapt novel means of testing. Perhaps some persons really wanted an STD test as quickly and easily as possible, whereas others with unusual symptoms or less obvious exposure to STDs may be more interested in a physical exam as part of their overall assessment. Thus, the data do not support conclusions that easier methods would improve testing among individuals who are already prone to delay, although further research is needed to confirm this finding.

Several limitations deserve mentioning. Our assessment of delay in seeking care was based on self-report and our measures of STD-related attitudes and beliefs were not from a validated scale. As study participants were recruited from an STD clinic setting, results may not be generalizable to persons utilizing other sources of care or even to all STD clinics; however, STD clinics continue to be a primary focus of STD-related testing and care for high-risk populations and most barriers to care are likely to be similar. Furthermore, we were unable to distinguish those who were referred by a health care provider from those who were referred by a friend or colleague. Of note, nearly half of the participants in our study were Caucasian or white, perhaps due to the proximity of the STD clinic to several colleges and universities, although we did not find significant differences in delay according to race.

Persons were categorized by a 7-day delay interval to enhance comparability to other studies, although the selection of a specific cut point for delay is somewhat arbitrary and not based on specific clinical outcomes. We also analyzed the delay interval as a continuous variable and obtained similar results (data not shown). Due to the crosssectional design, it is difficult to establish a temporal relationship between the associated factors and the outcome of delay. Thus, the possibility that delayed care-seeking resulted in the development of symptoms must also be considered. This is because we don't know when symptomatic persons acquired an infection. While a limitation of our research is that data from the study were collected ten years ago, they are still relevant today as the options for community-based STD testing and treatment have remained relatively unchanged over the past decade and very little new information on test-seeking behavior has emerged over the past decade.

In conclusion, this study is consistent with others that found both individual and structural factors to be associated with time to seek care for STDs. We found no significant differences in overall delay in seeking care between young men and women. Our findings suggest the use of interventions that improve access to clinics and testing options, encourage symptomatic persons to seek medical care more rapidly, and address concerns about stigma could help reduce the time to seek care for STDs among high-risk youth. In addition, our findings indicate health care providers 
play an important role in ensuring at-risk patients seek care in a timely manner.

\section{CONFLICT OF INTEREST}

The authors confirm that this article content has no conflict of interest.

\section{ACKNOWLEDGEMENTS}

The study was supported by the National Institutes of Health (K23 AA00303-01).

\section{REFERENCES}

[1] CDC. Sexually transmitted diseases surveillance 2010. [cited 2011 Jan. 3]; Available from: http://www.cdc.gov/std/stats10/adol.htm.

[2] Weinstock H, Berman S, Cates Jr. W. Sexually transmitted diseases among American youth: incidence and prevalence estimates, 2000. Perspect Sex Reprod Health 2004; 36(1): 6-10.

[3] Thi Thu H, Ziersch A, Hart G. Healthcare-seeking behaviours for sexually transmitted infections among women attending the national institute of dermatology and venereology in Vietnam. Sex Transm Infect 2007; 83(5): 406-10.

[4] Voeten HA, O'Hara BH, Kusimba J, et al. Gender differences in health care-seeking behavior for sexually transmitted diseases: a population-based study in Nairobi, Kenya. Sex Transm Dis 2004; 31(5): 265-72.

[5] Meyer-Weitz A, Reddy P, Van den Borne HW, Kok G, Pietersen J. Health care seeking behaviour of patients with sexually transmitted diseases: determinants of delay behaviour. Patient Educ Couns 2000; 41(3): 263-74.

[6] Brackbill RM, Sternberg MR, Fishbein M. Where do people go for treatment of sexually transmitted diseases? Fam Plann Perspect 1999; 31(1):10-5.

[7] Celum CL, Bolan G, Krone M, et al. Patients attending STD clinics in an evolving health care environment: demographics, insurance coverage, preferences for STD services, and STD morbidity. Sex Transm Dis 1997; 24(10): 599-605.

[8] Hobbs MM, van der Pol B, Totten P, et al. From the NIH: proceedings of a workshop on the importance of self-obtained vaginal specimens for detection of sexually transmitted infections. Sex Transm Dis 2008; 35(1): 8-13.

[9] Xu F, Stoner BP, Taylor SN, et al, Use of home-obtained vaginal swabs to facilitate rescreening for Chlamydia trachomatis infections: two randomized controlled trials. Obstet Gynecol 2011; 118(2 Pt 1): 231-9.

[10] Kress WJ, J DM, Sabu M, et al, Larsenianthus, a new Asian genus of Gingers (Zingiberaceae) with four species. PhytoKeys 2010; (1):15-32.

[11] Cook RL, Ostergaard L, Hillier SL, et al, Home screening for sexually transmitted diseases in high-risk young women: randomised controlled trial. Sex Transm Infect 2007; 83(4): 28691.

[12] Barth KR, Cook RL, Downs JS, Switzer GE, Fischhoff B. Social stigma and negative consequences: factors that influence college students' decisions to seek testing for sexually transmitted infections. J Am Coll Health 2002; 50(4): 153-9.

[13] Parrish DD, Kent CK. Access to care issues for African American communities: implications for STD disparities. Sex Transm Dis 2008; 35(12 Suppl): S19-22.

[14] Ireland JA, Reid M, Powell R, Petrie KJ. The role of illness perceptions: psychological distress and treatment-seeking delay in patients with genital warts. Int J STD AIDS 2005; 16(10): 667-70.
[15] Cunningham SD, Kerrigan D, Pillay KB, Ellen JM. Understanding the role of perceived severity in STD-related care-seeking delays. J Adolesc Health 2005; 37(1): 69-74.

[16] Crosby RA, Yarber WL, Meyerson B. Perceived monogamy and type of clinic as barriers to seeking care for suspected STD or HIV infection: results from a brief survey of low-income women attending Women, Infants, and Children (WIC) clinics in Missouri. Sex Transm Dis 1999; 26(7): 399-403.

[17] Chacko MR, Wiemann CM, Kozinetz CA, et al. New sexual partners and readiness to seek screening for chlamydia and gonorrhoea: predictors among minority young women. Sex Transm Infect 2006; 82(1): 75-9.

[18] Fonck K, Mwai C, Ndinya-Achola J, Bwayo J, Temmerman M. Health-seeking and sexual behaviors among primary healthcare patients in Nairobi, Kenya. Sex Transm Dis 2002; 29(2): 106-11.

[19] Cook RL, Comer DM, Wiesenfeld HC, et al. Alcohol and drug use and related disorders: an underrecognized health issue among adolescents and young adults attending sexually transmitted disease clinics. Sex Transm Dis 2006; 33(9): 565-70.

[20] Association' AP. Diagnostic and statistical manual of mental disorders. $4^{\text {th }}$ ed. (rev ed). Washington DC: Am Psychiatry Association 2000.

[21] Radloff LS. The CES-D scale: a self report depression scale for research in the general population. Appl Psychol Meas 1977; 1: 385-401.

[22] Amaro H, Gornemann I. Health care utilization for sexually transmitted diseases: influence of patient and provide characteristics. In: Wasserheit J, Aral S, Holmes K, Hitchcock P, Eds. Research issues in human behavior and sexually transmitted diseases in the AIDS era, Washington DC: Am Soc Microbiol 1991; pp. 140-60.

[23] Fortenberry JD. Health care seeking behaviors related to sexually transmitted diseases among adolescents. Am J Public Health 1997; 87(3): 417-20.

[24] Mercer CH, Sutcliffe L, Johnson AM, et al. How much do delayed healthcare seeking, delayed care provision, and diversion from primary care contribute to the transmission of STIs? Sex Transm Infect 2007; 83(5): 400-05.

[25] Inc SI, SAS 2000, SAS Institute Inc.: Cary NC.2000.

[26] SPSS I. SPSS: Chicago, IL. 2010.

[27] Hook EW, $3^{\text {rd }}$ CM Richey, Leone P, et al. Delayed presentation to clinics for sexually transmitted diseases by symptomatic patients: a potential contributor to continuing STD morbidity. Sex Transm Dis 1997; 24(8): 443-8.

[28] Aral SO, Holmes KK. The epidemiology of STIs and their socia and behavioral determinants: industrialized and developed countries. In: Holmes KK, Sparling PF, Stamm WE, et al., Eds. Sexually transmitted diseases. NY: McGraw-Hill Companies, Inc 2008; pp. 53-92.

[29] Hogben M, Bloom F, McFarlane M, St Lawrence JS, Malotte CK Factors associated with sexually transmitted disease clinic attendance. Int J Nurs Stud 2004. 41(8): 911-20.

[30] Owens GM. Gender differences in health care expenditures, resource utilization, and quality of care. J Manag Care Pharm 2008; 14(3 Suppl): 2-6.

[31] Adams PF, Martinez ME, Vickerie JL. Summary health statistics for the U.S. population: National Health Interview Survey 2009, U.S.D.o.H.a.H. Services, Ed. National Center for Health Statistics, 2010.

[32] Vaidya V, Partha G, Karmakar M. Gender differences in utilization of preventive care services in the United States. J Womens Health (Larchmt) 2012; 21(2): 140-5. 